\title{
Mental healthcare programmes in Kenya: challenges and opportunities
}

\section{David M. Ndetei MBChB(Nairobi) DPM(London) MRCPsych FRCPsych(UK) MD(Nairobi)}

Professor of Psychiatry, University of Nairobi, and Director, Africa Mental Health Foundation (AMHF) emaildmndetei@mentalhealthafrica.com; dmndetei@uonbi.ac.ke

\begin{abstract}
The mental healthcare programmes in Kenya fall into four inter-related categories: service provision; training; research; policy and advocacy.
\end{abstract}

\section{Service provision and training}

Service provision and training in mental health are interconnected. Currently, Kenya has 67 psychiatrists for an estimated population of 35 million, giving a psychiatrist-to-population ratio of 1:522400. In mid-1997, Kenya had 53 psychiatrists for an estimated population of 28.8 million, or 1:543400. Thus, there has hardly been any improvement in the ratio over the last 10 years, despite an enormous allocation of resources for the training of psychiatrists. Some of the contributing factors are high population growth and migration (Ndetei et $a l, 2007)$. Most of the other countries in sub-Saharan Africa have one psychiatrist serving a population of between 1000000 and 7000000 . In Nigeria the estimated ratio was 1:1000000 in 1997 and 1:1600000 in 2007 (Ndetei et al, 2007). However, the overall national ratios can be highly misleading, since there is great variation within countries, as is illustrated by the situation in Kenya in April 2004 (Table 1).

The fact that the overall ratio has not improved over the short term and the uneven national distribution mean that Kenya will not have sufficient psychiatrists in the foreseeable future. This has far-reaching, almost radical, implications for both clinical practice and overall mental health policy. In the short to medium term (perhaps even over the next two or three decades), the role of psychiatrists in Kenya will be mainly to provide academic and managerial leadership, with the provision of clinical services delegated to mid-level health professionals (non-university graduates), including nurses, clinical officers (with 3-4 years of training in clinical medicine), occupational therapists and social workers. Others will include university graduates in paramedical specialties, such as counselling and clinical psychology.

Table 1 Distribution of psychiatrists by province in Kenya

$\begin{array}{lcrrl}\text { Province } & \begin{array}{l}\text { No. of } \\ \text { psychiatrists }\end{array} & \% & \text { Population } & \begin{array}{l}\text { Psychiatrist: } \\ \text { population ratio }\end{array} \\ \text { Nairobi } & 34 & 64.1 & 2143254 & 1: 63007 \\ \text { Central } & 3 & 5.7 & 3724159 & 1: 1241386 \\ \text { Coast } & 4 & 7.5 & 2487264 & 1: 621816 \\ \text { Eastern } & 5 & 9.4 & 4631779 & 1: 926355 \\ \text { North-Eastern } & 0 & 0 & 962143 & - \\ \text { Nyanza } & 1 & 1.9 & 4392196 & 1: 4392196 \\ \text { Rift Valley } & 5 & 9.4 & 6987036 & 1: 1397407 \\ \text { Western } & 1 & 1.9 & 3358776 & 1: 3358776\end{array}$

Source: Ndetei et al (2007).
These groups are less costly to train and will generally be available where their services are needed. Their training curricula will of necessity have significantly greater mental health input, so that their function in relation to mental health is as good as that in relation to other medical disciplines. Psychiatric nurse training is in place in Kenya, but it does not attract enough applicants to fill the training vacancies. Related to this is the common practice of most qualified psychiatric nurses being assigned general nursing duties, thus denying them the opportunity to serve in their areas of specialisation. At the moment, there are no clinical officers who have specialised in psychiatry and there is no training of psychiatric clinical officers. Yet, in Kenya, they offer the bulk of medical services. Their training should therefore be accorded top priority.

Another significant aspect of training is the equipping of medical students with adequate clinical skills in psychiatry so that their competence in psychiatry is at a par with their competence in other disciplines. Currently, Kenya produces about 300-400 medical graduates annually. The impact of training 300 medical graduates appropriately will be far greater than training five psychiatrists a year (the current average yearly output).

At the undergraduate level, training in mental health takes place in a few centres in Kenya. At the University of Nairobi it consists of 160 hours in the behavioural sciences and a total of 720 hours of formal lectures in clinical psychiatry, clinical exposure and tutorials during the fourth and fifth (final) years of medical school. The students must pass a university examination during their final year of study.

Postgraduate specialist training for psychiatrists is available only at the University of Nairobi. This training has been conducted since 1983. It consists of a 3-year programme, which is offered after a prerequisite 2- to 3-year pre-entry experience after graduation from the medical school. The students are required to write a research dissertation on a subject of their choice. Some of these dissertations have been published in peer-reviewed journals. After the students qualify in their postgraduate university examinations, a further 2 years of practice (during which they work independently) is required before they can be recognised as specialists in psychiatry.

Other mental-health-related postgraduate training programmes are in clinical psychology, psychiatric social work, substance misuse and psycho-trauma, all of which are undertaken at the Department of Psychiatry at the University of Nairobi. It is worth noting that all the teaching described above is carried out by a full-time staff of nine psychiatrists, one psychiatric social worker and two psychologists. The only office space and facilities available consist of three rooms 
measuring about $3 \mathrm{~m} \times 3 \mathrm{~m}$ and three computers, which have only recently been connected to the internet. Psychiatric training of registered nurses is conducted by the Kenya Medical Training College but registration for this course is currently below the stipulated quota. Several public and private universities and colleges offer training in counselling psychology.

Finally, it has been suggested that traditional and faith healers play a significant role in mental health (Ndetei et al, 2007). Working with them and improving their skills through simple diagnostic training without seeming too keen to understand their trade (which they guard) may win their confidence and improve collaboration and referrals to the formal mental health services.

\section{Research, policy and advocacy}

There is still a lot that is not known about the prevalence rates of the whole spectrum of mental health problems across the continuum of life, in different situations and environments, for example poverty and mental illness, and how these complement each other. Other areas not yet adequately researched are the people who come into contact with the law, particularly prison populations, orphans, and community mental health and well-being. Research on the provision of good, affordable, accessible and appropriate services in particular socio-cultural and economic contexts should also be conducted. Research on simple issues of concern such as the regional distribution of psychiatrists within the country over time has led to the stark realisation that, rather than waiting until there are enough psychiatrists, radical policy strategies on how best to meet the service and training needs of Kenya have to be devised. Although some progress has been made through research in schools on issues such as substance use and misuse, psycho-trauma and anxiety and depressive disorders, there is still much that needs to be done.

Research is necessary not only for good practice but also for appropriate, evidence-based policies that are costeffective. The final policy makers (the politicians) will listen to technocrats only if the latter are armed with locally generated evidence that relates to the mental health of the electorate (which is what the politicians value most).

In Kenya today, a lot of mental health research is done through masters and doctoral theses, mainly in the Department of Psychiatry at the University of Nairobi and a few departments in other universities which offer health-related courses. The remaining (non-dissertation) mental health research is done mainly by a few individuals and nongovernmental organisations (NGOs). Notable among the NGOs is BasicNeeds UK (Kenya), which spearheads research in mental health in relation to poverty. Through this programme, a community research laboratory in an urban area has now been put in place and a rural one is being considered. It will be possible to conduct epidemiological research on community mental health and well-being across the continuum of life, as well as to carry out intervention studies through these laboratories; in due course these studies can be replicated in other parts of the country.

At present, most of the research related to mental health is being undertaken by the Africa Mental Health Foundation (AMHF), which brings together interested researchers from different backgrounds and different universities within and outside Kenya. The AMHF fosters collaborative research and supports research by BasicNeeds UK (Kenya) and other international collaborators. It also supports annual award schemes for outstanding students in mental health/psychiatry (both clinical and research) at the University of Nairobi and the best nurse in mental health.

Perhaps the most significant recent development is the formation of the University of Nairobi's Medical Students Association for Research and Statistics. The Association has plans to extend to other medical schools within the region and also to foster collaboration with similar organisations world-wide. Its patron is the author, and one of the main objectives is to sensitise students to the importance of research during their formative years.

\section{Reference}

Ndetei, D. M., Ongecha, F. A., Mutiso, V., et al (2007) The challenges of human resources in mental health in Kenya. South African Psychiatry Review, 10, 33-36.

\section{Provision of mental health services in Nigeria}

\section{Olufemi Olugbile, M. P. Zachariah, O. Coker, O. Kuyinu and B. Isichei}

Lagos State University Teaching Hospital, Ikeja, Lagos State, Nigeria, email femi_olugbile@yahoo.com

$\mathrm{N}$ igeria, like other African countries, is short of personnel trained in mental healthcare. Efforts to tackle the problem have often focused on increasing the numbers of psychiatrists and nurses in the field. These efforts, over the past 20 years, have not appeared to have greatly improved service delivery at the grass roots. Most of the specialist centres where such highly trained personnel work are in urban areas and for a large part of the population access to them is limited by distance and cost.

Mental healthcare is one of the recognised elements of primary healthcare in Nigeria. Primary health centres (PHCs) are supposed to have a reasonable amount of competence in recognising and dealing with some of the more common mental disorders. They are the first point of contact for many 